\title{
A crítica marxista ao desenvolvimento (in)sustentável
}

\author{
Rosana de Carvalho Martinelli Freitas \\ Universidade Federal de Santa Catarina (UFSC)
}

Camila Magalhães Nélsis

Universidade Federal de Santa Catarina (UFSC)

\author{
Letícia Soares Nunes \\ Universidade Federal de Santa Catarina (UFSC)
}

\section{A crítica marxista ao desenvolvimento (in)sustentável}

Resumo: O presente artigo tem como objetivo apresentar as implicações teóricas e os desdobramentos da concepção de desenvolvimento sustentável, com ênfase na elucidação das diferenças na sua compreensão e utilização. A partir da revisão bibliográfica, inicialmente, recupera-se a apreensão de Marx sobre a relação homem, natureza e capitalismo. Na sequência, apresentam-se abordagens marxianas críticas à concepção do desenvolvimento sustentável, a qual, embora usual, é ambígua e motivo de muitas controvérsias. Finalmente, evidenciam-se os aspectos para um novo tratamento às questões ambientais face à insustentabilidade, inerente ao modo de produção capitalista e à destrutividade que o acompanha.

Palavras-chaves: Questão socioambiental. Desenvolvimento sustentável. Marxismo.

\section{Marxist Criticism of (Un)sustainable Development}

Abstract: The purpose of this article is to present the theoretical implications and consequences of the concept of sustainable development, with an emphasis on the elucidation of differences in their understanding and use. Based on a bibliographic review, the paper first reviews Marx's understanding about the relationship between man, nature and capitalism. It then presents Marxist approaches that are critical of the concept of sustainable development, which, although commonly used, is ambiguous and the motive of considerable controversy. Finally, factors are present for a new approach to environmental issues considering the unsustainability inherent to the capitalist mode of production and the destruction that accompanies it.

Keywords: Socio-environmental question. Sustainable development. Marxism. 


\section{Introdução}

Organismos internacionais, como o Banco Mundial, a Organização Mundial do Comércio (OMC), as Organização das Nações Unidas (ONU), prescrevem, com maior ênfase nas duas últimas décadas, aos países considerados "subdesenvolvidos ou em desenvolvimento" indicações e determinações com o objetivo, em princípio, de resolver os problemas da desigualdade econômica dos e entre os países. Entre as prescrições, identifica-se a adesão ao capital externo, reiterando a possibilidade de um desenvolvimento sustentável que compatibilize crescimento econômico, desenvolvimento humano e qualidade ambiental.

Este artigo tem como objetivo central apresentar elementos relevantes à fundamentação e à compreensão da crítica ao desenvolvimento sustentável e à sustentabilidade, tal como expresso no Relatório Brundtland.

Na primeira seção, tendo como referência fragmentos dos escritos de Karl Marx, são expostos aspectos fundamentais da correlação entre natureza, sociedade e desenvolvimento. Salienta-se que Marx não abordou o tema natureza do ponto de vista puramente biológico. Este tema está presente no decorrer de toda a sua obra. Na sequência, apresenta-se a crítica ao desenvolvimento (in)sustentável. Esta se contrapõe àqueles que postulam que o marxismo é uma teoria e uma filosofia que não tem muito a contribuir com a atual discussão da questão ambiental, na sua intersecção com modelos de desenvolvimento, sobretudo na sociedade capitalista ${ }^{1}$. Neste sentido, destaca-se que nos últimos anos diversos autores $^{2}$, a partir de uma perspectiva crítica, vêm tratando sobre o tema natureza ${ }^{3}$, marxismo e desenvolvimento, estabelecendo relações e fundamentos para a educação ambiental, ecologia política, economia ambiental, e para as demais áreas e campos do conhecimento.

Argumenta-se neste artigo, ${ }^{4}$ que o termo desenvolvimento sustentável e sua utilização, ainda, permanecem inseridos em um debate "asséptico, a-histórico", decorrente da falta de clareza semântica e conceitual, comprometendo perspectivas analíticas que não referenciam as diferenças entre as e das sociedades contemporâneas. Atribui-se tal situação às circunstâncias derivadas, especialmente, da diversidade de interesses e opiniões ligadas às diferenças socioeconômicas, políticas e geopolíticas, que antecederam a formulação e concepção deste termo.

\section{Capitalismo e destrutividade socioambiental}

Todas as sociedades, segundo Marx e Engels (1988, p. 76), tiveram suas histórias baseadas nas lutas de classes: "Homem livre e escravo, patrício e plebeu, barão e servo, mestre de corporação e companheiro, numa palavra, opressores e oprimidos, em constante oposição, têm vivido numa guerra ininterrupta". A sociedade burguesa que surge com a decadência da sociedade feudal aboliu os antagonismos estamentais do feudalismo, transfigurando-os na diferença de classes capitalistas, na exploração e opressão de uma classe sobre outra e na exploração dos recursos naturais.

As mudanças ocorridas no decorrer do século 18, com a consolidação do modo de produção capitalista, acarretaram profundas alterações na relação do homem com a natureza. Marx (1996, p. 113), discorrendo sobre a guerra travada pelo capital, para arrancar o campesinato da terra e para submeter a atividade agrícola à lógica mercantil, denunciou a exploração dos recursos naturais das colônias, que propiciou o enriquecimento de uma parcela da burguesia e intensificou a destruição desses recursos, sobretudo, nos países do hemisfério sul.

Com a preponderância sempre crescente da população urbana que amontoa em grandes centros, a produção capitalista acumula, por um lado, a força motriz histórica da sociedade, mas perturba, por outro lado, o metabolismo entre homem e terra, isto é, o retorno dos componentes da terra consumidos pelo homem, sob forma de alimentos e vestuário, a terra, portanto, a eterna condição natural de fertilidade permanente do solo. Com isso, ela destrói simultaneamente a saúde física dos trabalhadores urbanos e a vida espiritual dos trabalhadores rurais. [...] E cada progresso da agricultura capitalista não é só um progresso na arte de saquear o trabalhador, mas ao mesmo tempo na arte de saquear o solo, pois cada progresso no aumento da fertilidade por certo período é simultaneamente um progresso na ruína das fontes permanentes dessa fertilidade.

Para melhor compreensão da questão, faz-se menção ao conceito de "fratura metabólica" que expressa a alienação entre o homem e a natureza que se dá pela especificidade do trabalho e de toda a cadeia produtiva, quando desenvolvidas no sistema capitalista. Para Marx, a natureza e o homem possuiriam um metabolismo único, esta seria o corpo inorgânico desse, e, com a alienação do próprio ser no capitalismo, ocorreria um distanciamento visceral entre ambos, estabelecendo a denominada "fratura metabólica". Marx e Engels, enquanto primeiros a aplicarem o conceito de metabolismo à sociedade, associaram o referido termo à relação cidade-campo, grande indústria-grande agricultura, homem-natureza, e a "falha" estariam na insustentabilidade destes relacionamentos dentro do capitalismo. 
Foster (2010) retoma o conceito marxiano de metabolismo homem-natureza (MARX, 1844) e salienta que, mediado pelo trabalho, o homem transforma a natureza e, nesse movimento, também se transforma. $\mathrm{O}$ trabalho é um processo entre o homem e a natureza. Um processo em que o homem, por sua própria ação, media seu metabolismo com a natureza. Ao mesmo tempo em que o homem se diferencia da natureza pelo trabalho, torna-se alienado diante do trabalho e em relação à natureza.

Marx, descrevendo sobre as revoluções agrícolas, denunciava o saque de nutrientes dos solos estrangeiros para favorecer a agricultura inglesa, já com seu solo bastante deteriorado. Seu olhar bastante crítico verificava a dominação exercida politicamente e militarmente sobre as colônias inglesas para assegurar matéria prima e, futuramente, mercado consumidor (FOSTER, 2010). As antigas colônias europeias, hoje países "em desenvolvimento" ou "subdesenvolvidos", forneceram as condições materiais adequadas para o fortalecimento do capitalismo nos países "desenvolvidos", sofrendo por anos a expropriação de seus recursos naturais. Ou seja, Marx (1996) sinalizava que a descoberta e a exploração das colônias propiciaram o enriquecimento de uma parcela da burguesia, importante para o desenvolvimento do capitalismo emergente.

A descoberta das terras de ouro e de prata na América, o extermínio, a escravização e o enfurnamento da população nativa nas minas, o começo da conquista e a pilhagem das Índias Orientais, a transformação da Africa em um cercado para a caça comercial às peles negras, marcam a aurora da era de produção capitalista. Esses processos "idílicos" são momentos fundamentais da acumulação primitiva (MARX, 1996, p. 370).

Para se entender, atualmente, o impasse no qual se encontram os "países do sul", segundo Chesnais e Serfati (2003), é necessário inscrevê-los na longa história da dominação capitalista. No quadro da divisão internacional do trabalho, esses países, colonizados ou não, foram fornecedores de recursos naturais para os grupos industriais das "metrópoles". Para os autores,

A conquista de novos mercados e o emprego de uma mão de obra superexplorada, utilizada no local ou importada foram igualmente os motores da expansão capitalista do século dezenove e do início do século vinte (CHESNAIS; SERFATI, 2003, p. 33).

\section{A história do capitalismo é produto}

[...] da interação, da imbricação, da intercorrência do desenvolvimento de forças produtivas, de alternações nas atividades estritamente econômicas, de inovações tecnológicas e organizacionais e de processos sociopolíticos e culturais que envol- vem as classes sociais (PAULO NETTO; BRAZ, 2007, p. 170).

Ou seja, a burguesia formada por uma pequena parcela detentora da riqueza em forma monetária e dos meios de produção, e o proletariado, majoritariamente empobrecido, "livre" e ao mesmo tempo obrigado, pela necessidade, a vender a única mercadoria que possui: sua força de trabalho, em troca de salários.

Assim, no transcorrer de séculos a dependência dos países periféricos em relação aos centrais ainda está associada à exploração de seus recursos naturais, constituindo o Estado um ente indispensável a esse processo. Embora as condições sejam desiguais entre os países do "norte e do sul", estes se submetem àqueles. Ambos financeiramente ganham com isto. Embora ganhem menos, os "países do sul" garantem a produção e a reprodução dos países industrializados às custas da produção primária, da riqueza e das variedades ambientais. A degradação ambiental, como relembra Leff (1994), acentuou-se nas regiões onde, historicamente, as formações sociais, sobretudo os ecossistemas tropicais, foram explorados pelos países capitalistas industrializados. A mundialização do capital, por um lado, gerou o "subdesenvolvimento" dos países ditos "em desenvolvimento" e "subdesenvolvidos", resultante da divisão internacional do trabalho, do intercâmbio desigual de mercadorias e da degradação ambiental, e, por outro, forneceu bases materiais para a acumulação de capital dos países "desenvolvidos".

Neste contexto, Mészáros (2003), igualmente, sinalizará o quanto o ambiente tornou-se um importante elemento no que tange às trocas desiguais entre os Estados-nação e a relação desenvolvimento/subdesenvolvimento ou norte/sul. Aspecto fundamental, subestimado na discussão sobre o desenvolvimento sustentável.

Apreende-se que o desenvolvimento econômico do capitalismo sempre acarretou a degradação social e ecológica, será, no entanto, nas três últimas décadas que as manifestações das insustentáveis relações com o planeta constituíram um conjunto de contradições que levaram à identificação da denominada "crise ambiental". Esta tem sido definida, principalmente, por meio das mudanças climáticas, como o aumento da temperatura da Terra em decorrência do efeito estufa, as devastações das florestas tropicais, a redução da biodiversidade, as exaustões e contaminações dos solos, das águas e dos mares, as extinções de animais, relacionadas em alguma medida com o aumento dos desastres socioambientais, aumento da população, urbanização e uso de energias com base em recursos não renováveis.

É possível identificar duas grandes tendências para o que vem sendo denominada crise ecológica e/ ouambientalista, no que se refere às suas conse- 
quências. Uma delas, de caráter conservador, assume que é possível reverter a atual situação de crise adotando-se o desenvolvimento sustentável como princípio estruturante do processo de desenvolvimento. A outra tendência, de visão transfor-madora, assume que as raízes da crise estão no padrão civilizatório eurocêntrico, portador da ideia de progresso imposto aos povos do planeta pela colonização. Enquanto Burkett (1999), Foster e Clark (2004) entendem que o capitalismo gera um conjunto de contradições ecológicas que, em escala planetária, colocam em perigo a biosfera em sua totalidade, ou seja, apreendem que a referida crise poderia levar a uma crise do sistema capitalista, Chesnais e Serfati (2003) rejeitam a ideia de que pelo viés da destruição ou de danos graves ao ambiente natural, o capitalismo estaria em perigo, e até destruiria suas próprias condições de reprodução e de funcionamento enquanto capitalismo.

Será, igualmente, na crítica das abordagens da chamada crise ambiental que Foladori (1999) e Coutinho (2009), entre outros, alertarão para o fato do termo ser utilizado de forma descontextualizada do avanço do modo de produção capitalista, por não haver a associação da "crise ambiental” à produção capitalista e à destruição da natureza.

Mészáros (2007) relaciona a crise sistêmica do capital e a crise denominada ambiental, apontando a finitude dos recursos naturais/energia, os problemas de poluição e as mudanças climáticas como parte do que denomina de limites absolutos do sistema do capital.

Face às propostas para a superação da denominada crise ambiental, Loureiro (2006a, p. 11) afirma que a solução não se restringe à descoberta de tecnologias limpas, nem às mudanças comportamentais, mas é necessário uma

[...] reorganização da base civilizacional e da estrutura política, econômica social e cultural, vigente nas sociedades instituídas no período posterior à Revolução Industrial e no marco da modernidade capitalista.

Salienta-se que Marx acreditava que apenas um sistema socialista e comunista proporcionaria o desenvolvimento econômico voltado à satisfação das necessidades básicas humanas. Nesse sistema não haveria a produção de excedentes e supérfluos visando unicamente ao lucro, o que alteraria positivamente a relação homem e natureza ${ }^{5}$.

\section{A crítica ao desenvolvimento (in)sustentável}

É consenso entre os pesquisadores que a primeira grande manifestação internacional, cujo debate sobre a questão ambiental alertou os países a inseri- rem a temática no centro de suas políticas públicas, foi a Primeira Conferência Mundial para o Meio Ambiente e Desenvolvimento Sustentável, promovida em 1972 pela ONU, em Estocolmo.

Na década de 1980, criou-se a Comissão Mundial sobre o Meio Ambiente e Desenvolvimento (CMMAD), pela Assembleia Geral da ONU, presidida por Gro Harlem Brundtland. Essa Comissão, em 1987, lançou o relatório Nosso Futuro Comum, conhecido também como Relatório Brundtland. Nesse relatório, o termo desenvolvimento sustentável foi definido como "[...] o desenvolvimento que satisfaz as necessidades presentes sem comprometer a capacidade das gerações futuras de suprirem suas próprias necessidades" (CMMAD, 1991, p. 7). Estão implícitas no Relatório a noção de limites ao desenvolvimento e a ênfase de que os países ditos "em desenvolvimento" não poderiam seguir o mesmo ritmo de crescimento econômico dos países "desenvolvidos", pois os recursos naturais necessários estariam ameaçados. A concepção de desenvolvimento sustentável descrita no relatório hegemonicamente está presente em encontros acadêmicos, nas produções técnicas, científicas, em conferências. A compreensão sobre sua origem e consequências é motivo de disputa, divergências, imprecisões (RAMOS, 2010; FREITAS, 2010).

Embora o aprofundamento e a visibilidade nos debates em torno de uma proposta de desenvolvimento sustentável tenham ocorrido a partir do Relatório Brundtland, o processo que levou à sua adoção é anterior. Godard (1997) e Frey (2001) apresentam três abordagens teóricas existentes no meio científico e no dos especialistas vinculados à análise do desenvolvimento econômico e de suas consequências sobre a natureza.

A primeira abordagem, denominada "econômicoliberal de mercado" parte do pressuposto de que "pressão de concorrência, crescimento econômico e prosperidade levariam automaticamente ao uso racional dos recursos naturais, ao progresso tecnológico e às novas necessidades de consumo compatíveis com as exigências do meio ambiente."

A segunda abordagem de pensamento, denominada de "ecológico-tecnocrata de planejamento" (BANCO MUNDIAL, 1994; SACHS, 1986; OPHULS; BOYAN JR, 1992; HEILRONER, 1974 apud FREY, 2001), é composta por várias correntes de pensamento, entre elas o ecodesenvolvimento ${ }^{7}$. Em síntese, tem-se nessa abordagem a proposta de compatibilidade do desenvolvimento econômico com a preservação dos recursos naturais, e que estes devem ser alvo prioritário da intervenção estatal. Seus resultados conduzem ao que se pode chamar de "biocêntrica", "bioeconomia" ou "economia ecológica". A postura biocêntrica encontra-se também na concepção filosófica da deep ecology. Esta interpretação vem sendo identificada 
por sua "postura tecnocrata e centralizadora" (FREY, 2001, p. 5) e teria sido a que se sobrepôs às discussões que fundamentaram o Relatório Brundtland. $\mathrm{Na}$ divisão ecológica internacional, segundo Fernandes (2002), após a publicação do Relatório Brundtland, a proposta do ecodesenvolvimento, presente na Conferência de 1972 em Estocolmo, caiu em descenso.

A terceira abordagem denominada "política de participação democrática", seria decorrente do prolongamento da teoria neoclássica do equilíbrio e do crescimento econômico. É composta por diferentes autores, entre eles Leff (1992).

Particularmente no contexto dos problemas dos países em desenvolvimento - almeja antes de tudo a defesa da humanidade ou uma vida digna para todos, o que, como consequência, deveria propiciar também uma harmonia maior com a natureza (FREY, 2001,p. 13).

Cabe ressaltar que, desde 1972, várias tentativas recolocavam no cenário internacional um novo conceito de desenvolvimento - resultaram, inclusive, nas formulações denominadas de "outro desenvolvimento", "desenvolvimento endógeno" e "ecodesenvolvimento". Contudo, elas não atendiam plenamente às expectativas políticas dos órgãos e das instituições internacionais, que necessitavam de uma concepção capaz de proporcionar um alinhamento em torno da possibilidade de unir meio ambiente e crescimento econômico, sem questionar a continuidade do sistema.

Nas três abordagens, há aspectos que não podem ser negligenciados, contudo, para fins deste artigo, privilegiou-se a crítica à concepção de desenvolvimento sustentável do Relatório Brundtland.

Visando adensar a discussão e elucidar a complexidade na qual a concepção de desenvolvimento sustentável, Porto-Gonçalves (2004, p. 39) problematizará algo anterior ao conceito, ou seja, o significado do termo desenvolver:

[...] desenvolver é tirar o envolvimento (a autonomia) que cada cultura e cada povo mantêm com seu espaço, com seu território; é subverter o modo como cada povo mantém suas próprias relações de homens (e mulheres) entre si e destas com a natureza; é não só separar os homens (e mulheres) da natureza como também separá-los entre si, individualizando-os, o que envolve uma nova configuração societária, a capitalista e, portanto, mercantil [...].

Para este mesmo autor (1996, p. 43), a concepção de desenvolvimento sustentável "[...] tenta recuperar o desenvolvimento como categoria capaz de integrar os desiguais (e os diferentes?) em torno de um futuro comum. Isto demonstra que pode haver mais continuidade do que ruptura de paradigmas no processo em curso."

Lafferty (1996) e Lenzi (2005) enfatizarão a importância de se compreender o que deve ser sustentável como uma questão de ordem moral e, mediante esta definição, a discussão se relacionaria à forma de garantir a sustentabilidade e às questões de justiça e democracia. Apresentam o conceito de desenvolvimento sustentável com características políticas e normativas, destacando preocupações com os problemas ambientais globais, com a interdependência ecológica global, com a justiça social (nacional e global), com a interligação entre questões de sustentabilidade e justiça, bem como com os países pobres e com a exigência de uma mudança econômica estrutural (crescimento econômico submetido ao desenvolvimento sustentável e com ênfase no papel do governo).

Layrargues (1997, p. 5), aprofundando o debate crítico a respeito do termo desenvolvimento sustentável, há mais de uma década sinalizava

\section{[...] no atual estado do desenvolvimento tecnoló- gico, considerando suas implicações ambientais, o padrão de consumo do Primeiro Mundo definitiva- mente é insustentável e não generalizável ao con- junto da humanidade ${ }^{8}$.}

A crítica à concepção de desenvolvimento sustentável também está presente em Mészáros (2001, p. 8). Para o autor, o próprio "desenvolvimento" na lógica capitalista é insustentável, sendo, portanto, impossível pressupor desenvolvimento sustentável sem superar a desigualdade substantiva, o modo de produção hegemônico e as dificuldades estruturais nele existentes; remete à possibilidade do desenvolvimento sustentável, condicionando-a a:

\section{[...] estarmos realmente no controle dos processos culturais, econômicos e sociais vitais, através dos quais os seres humanos não só sobrevivem, mas também podem encontrar satisfação, de acordo com os objetivos que colocam para si mesmos, em vez de estarem à mercê de imprevisíveis forças naturais e quase-naturais determinações socioeconômicas.}

Ainda para o referido autor, o desenvolvimento sustentável tem o imperativo da eliminação do desperdício e da existência de uma economia racional com base no controle interno e autodirigido. Mészáros utiliza o conceito de "desigualdade substantiva" para aludir à desigualdade estrutural e à adversidade existentes no capitalismo. A desigualdade substantiva seria reforçada pela interação recíproca entre estruturas materiais reprodutivas desiguais e dimensão cultural que contiveram o indivíduo no pequeno do- 
mínio de ação. O contraponto à "desigualdade substantiva" seria a cultura da "igualdade substantiva". Esta se reportaria a uma direção emancipatória pelo "envolvimento ativo de todos e consciência da própria partilha de responsabilidade implícita na operação de tal modo de tomada de decisões semadversariedade" (MÉSZÁROS, 2001,p. 9).

Em uma posição muito próxima, Mota e Silva (2009) e Ramos (2010) criticam aqueles que defendem a possibilidade da criação de práticas socioeconômicas capazes de operar transformações expressivas na relação sociedade e natureza, à luz do desenvolvimento sustentável capitalista.

Ramos (2010, p. 4) infere que Marx:

[...] pensa uma sociedade regida por relações sociais na base da propriedade coletiva e de produtores livremente associados. Esta sociedade certamente usará a racionalidade no sentido do desenvolvimento sustentável, porque terá como objetivo produzir bens para o usufruto segundo a necessidade de cada um, e não para produzir objetos para serem trocados e, consequentemente, visando ao acúmulo de riqueza concentrada na mão de poucos (os detentores de capital).

A autora (2010, p. 7) enfatiza que

[...] sob o ponto de vista das relações de produção capitalista é impossível qualquer modalidade de desenvolvimento sustentável, com vigência ampla e duradoura e que venha salvaguardar os recursos naturais e humanos do planeta Terra.

Embora a autora se sustente em uma abordagem marxista, não refuta a denominação "desenvolvimento".

Por sua vez, Mota e Silva (2009), enfatizam a ausência de uma crítica radical e classista à problemática ambiental e o quanto isto tem contribuído para a construção de um consenso que unifique interesses de classes antagônicas em torno da defesa do desenvolvimento sustentável. Para elas, o desenvolvimento sustentável é aquele que permite reverter a dinâmica de uso dos recursos e dos serviços ambientais, equilibrando a velocidade de utilização e de recomposição dos ecossistemas; é a conjugação entre a sustentabilidade ambiental e social - faces do mesmo processo -, que apenas se realizarão quando o capitalismo for ultrapassado; e implica o respeito à natureza e à igualdade social.

As referidas autoras destacam, ainda, que embora a superação da sociedade de classes e da lógica da acumulação de riqueza seja basilar para a construção de uma sociabilidade emancipada, é preciso desconstruir o produtivismo histórico, imbricado no sistema capitalista. Nesse contexto, faz-se necessá- ria a superação de concepções que "ora confinam o debate ambiental à sua dimensão econômica e ecológica, ora negam a dimensão ambiental como parte da questão social" (MOTA; SILVA, 2009, p. 46).

Tal como concebido hegemonicamente, o desenvolvimento sustentável é uma ideologia que "unifica os interesses dos trabalhadores, dos empresários e do Estado em torno da defesa de uma pretensa sustentabilidade ambiental, social e econômica" (MOTA; SILVA, 2009, p. 39), pois essa residiria no apelo à preservação da natureza, ao enfrentamento da desigualdade social e ao comprometimento individual e coletivo da sociedade com a natureza, ignorando as determinações históricas do processo destrutivo.

A ideia de desenvolvimento, tal como existe na sociedade moderno-colonial, é questionada por Porto-Gonçalves (2004), pois pressupõe a dominação da natureza. $\mathrm{O}$ autor sinaliza a importância de determinadas condições jurídicas e políticas para novas formas de dominação que não só prolonguem, mas intensifiquem os processos anteriores de apropriação destrutiva da natureza. Ou seja, mesmo diante dos graves problemas, são apresentadas propostas como "plante uma árvore", "promova a coleta seletiva do lixo" ou "desenvolva o ecoturismo".

No esteio das discussões sobre as questões ambientais, a necessidade de se apreender a sustentabilidade como algo viabilizado e regulado por instituições econômicas e políticas, que garantam condições ecológicas para a realização de direitos políticos e sociais, suscitou o debate dos direitos ambientais, ou seja, o direito ao meio ambiente ecologicamente equilibrado, bem como de uso comum do povo e essencial à sadia qualidade de vida, impondo ao poder público e à coletividade o dever de defendê-lo para as presentes e futuras gerações ${ }^{9}$.

Estão presentes neste debate aspectos referentes à concepção e às formas de prevenir, reparar o meio ambiente, garantir qualidade de vida, bem como a participação popular e a publicidade. Sob esse ponto de vista, alguns teóricos, a exemplo de Leff (1994), estabelecem uma relação estreita entre sustentabilidade e democratização, pois não seria possível apreender a primeira sem deliberação pública, o que coloca em questão os limites da democracia representativa na contem-poraneidade na sua interface, ou não, com o desenvolvimento sustentável.

Leff (1994) parte do pressuposto de que as sociedades "modernas", tanto capitalistas quanto socialistas, seriam produtivistas e antiecológicas. Tratar-se-iam de sociedades nas quais a natureza não é considerada dentro da racionalidade econômica e, portanto, seriam insustentáveis. A busca de uma racionalidade ambiental, segundo o autor, deve ter como objetivo detectar aqueles elementos que possam se constituir em base de uma estratégia produtiva alternativa, onde a natureza integre-se à lógica 
produtiva. Para Leff (1994), a sustentabilidade ambiental está diretamente relacionada à satisfação das necessidades básicas das populações e essas se associam aos padrões de uso dos recursos naturais, com seus processos de produção e consumo. Para o mesmo, a satisfação das necessidades básicas depende de uma estratégia de desenvolvimento sustentável, capaz de promover atividades produtivas que permitam um aproveitamento ecologicamente racional dos recursos naturais, reduzindo os custos ecológicos.

A mesma natureza, explorada ilimitadamente durante os séculos 19 e 20, adentra o século 21 valorizada como condição necessária à sustentabilidade da produção e ao potencial produtivo dos países. Neste sentido, os organismos financeiros internacionais, atentos às novas perspectivas ambientais mundiais, têm desempenhando um papel central no debate influenciando as diretrizes políticas e econômicas, direcionadas aos chamados "ajustes estruturais" dos países periféricos. Passaram a exigir a consolidação de uma legislação ambiental como condição para empréstimos internacionais para os países "em desenvolvimento" ou "subdesenvolvidos", além de estudos ambientais, que incluíssem a análise de impactos sociais e todas as problemáticas a eles inerentes (REIS; BLOEMER, 2001; SANCHÉS, 2000).

Para Loureiro (2006b), desde que foi criada a Comissão de Desenvolvimento Sustentável, no âmbito da ONU, essa não conseguiu dinamizar a questão ambiental em seu interior, ficando a temática subordinada aos mecanismos de funcionamento da ONU e às suas relações de poder internas. Mesmo diante deste contexto de descrédito da ONU/ PNUD para promoção da sustentabilidade ambiental, e do seu próprio conceito dentro do sistema capitalista, a presença de financiamentos internacionais foi significativa para elaboração da legislação ambiental brasileira, especialmente após a transição do monopólio estatal e a abertura ao capital privado nacional ao internacional. Os projetos aprovados pela ONU/ PNUD ${ }^{10}$ possuem como objetivo implícito a internalização do conceito de sustentabilidade ambiental e a criação de parâmetros de sustentabilidade, criados e seguidos com o apoio técnico do Programa.

Pode-se afirmar que a legislação ambiental brasileira sofreu influências internacionais e à medida que as leis foram criadas, ao invés de serem revisadas e substituídas, foram sobrepostas, evidenciando confli- tos conceituais, falta de objetivos e desarticulação (SANCHÉS, 2008).

Assim, a concepção de desenvolvimento sustentável vem sendo adotada, amenizando as críticas ao capital.

Diante do posicionamento dos autores marxistas abordados, verifica-se que a sustentabilidade ambiental requer a construção de um novo modo de produção superior ao capitalismo. Averigua-se que o atual conceito de desenvolvimento sustentável tende a neutralizar a imagem nefasta do capital perante a degradação ambiental por ele provocada, dada a forte alienação entre homem e natureza intrínseca à fratura metabólica identificada por Marx e Engels.

\section{Incontrolabilidade do sistema e subserviência coletiva: a título de considerações finais}

Se a transformação da natureza em fonte de lucro desenhava-se desde a acumulação primitiva, é no capitalismo tardio que se evidenciam as profundas contradições desse processo, uma vez que os acentuados níveis de destrutividade impõem a adoção de novas táticas e estratégias visando a sua reprodução. A análise histórica da consolidação do capitalismo em escala planetária permite afirmar que os países periféricos forneceram os alicerces que os países de economia central precisavam para fortalecer o modo de produção capitalista.

A extração do excedente econômico ou a acumulação por expropriação dos países subdesenvolvidos pelos e para os países de economia central é vista para além de um simplificado problema de circulação ou relações mercantis, em que os países periféricos produzem matérias-primas para os países centrais e estes, manufaturas para aqueles. O fundamento da questão perpassa a formação do excedente e a mais-valia produzida pelos países periféricos, que sustentam os países centrais. A exploração e a pilhagem envolvidas nesse processo configuram o ciclo da produção e da reprodução da subserviência. As estruturas socioeconômicas e os sistemas políticos internos dos países periféricos auxiliam na autossabotagem, levando-os a repetitivas formas de dependência, de causas estruturais com amarras complexas.

Diferentemente de momentos pretéritos, em que os efeitos destrutivos da produção industrial sobre a natureza fizeram-se localizados (poluição de mares, devastação de florestas, extinção de espécies), no 
período atual, pesquisas promovidas pelas diversas instituições científicas e agências multilaterais demonstram que a natureza evidencia sinais de esgotamento de suas potencialidades, obstaculizando a expansão incessante da produção mercantil, tanto pela escassez de matérias-primas como pela dimensão dos danos sociais, políticos e econômicos causados à natureza (FREITAS, 2010; SILVA, 2010).

A crítica marxista problematiza contundentemente as relações produtivas alienadas da natureza vigentes no atual modelo de produção capitalista. Os objetivos do capitalismo, metamorfoseado em verde e humanizado, seriam a tentativa de naturalizá-lo como único sistema econômico possível e minimizar as críticas de cunho social e ecológico contrárias a ele, além de explorar o marketing dos produtos, serviços e selos verdes da falácia da responsabilidade socioambiental, promovendo a lucratividade das empresas pela imagem. Pode-se afirmar que o modo de produção capitalista está gerando um conjunto de contradições ecológicas. No plano econômico, o capital transforma a poluição industrial e a rarefação de recursos em novos campos de acumulação e, no espaço político, transfere o peso das degradações para os países periféricos e para as classes subalternas.

A superação da alienação dos homens com o trabalho e com o meio exterior (natural) que o cerca é um desafio para a sociedade que objetiva desenvolver-se de forma socialmente sustentável. Portanto, o tema natureza deverá se fazer presente na agenda de discussões marxistas com maior relevância.

Infere-se que há um consenso entre os autores marxistas acerca da unicidade e da interface entre a questão social e a origem e o agravamento dos problemas socioambientais. As ditas contradições intrínsecas do sistema capitalista propiciam a "fratura metabólica" anunciada por Marx, a qual se acirra com a mundialização e a financeirização do capitalismo; essa é a expressão do afastamento e da desarticulação da sociedade e da natureza, cada vez mais evidenciada.

Igualmente, infere-se que o conceito de desenvolvimento sustentável, segundo o Relatório Brundtland, coaduna com a harmonização de um pacto transclassista, sem formulação teórica necessária para tratar a questão da sustentabilidade ambiental. Enquanto o conceito de desenvolvimento sustentável propagado pela ONU/PNUD visa compatibilizar o crescimento econômico com o desenvolvimento humano e a qualidade ambiental, sem, contudo, referendar um projeto de superação do modo de produção hegemônico, por apostar que o capitalismo contém em si possibilidades de alcançar patamares mais humanizados e ecológicos; a crítica marxista problematiza contundentemente a alienação provocada pelas relações produtivas estabelecidas no capitalismo. Para ela, as soluções paliativas no tratamento das questões socioambientais constituem-se em estratégicas de fortalecimento ao próprio capitalismo.

Com base nas considerações realizadas, o desenvolvimento sustentável é propagado como única solução viável para solucionar problemas evidentemente relacionados às questões ambientais. Apreende-se, diante das abordagens quanto à conceituação de desenvolvimento sustentável, que é um processo em construção, no qual disputam várias correntes de pensamento do conhecimento científico.

A negação do termo desenvolvimento sustentável exige, ainda, esforços teóricos para a conceituação de um novo termo compatível com os anseios da crítica marxista. Identifica-se, igualmente, a possibilidade de ressignificação do termo associando-o a um novo modo de produção, superior ao capitalismo, mais ético, ecológico e voltado à superação das necessidades humanas e que respeite a simbiose metabólica entre homem e natureza. Tais esforços são vistos em Mészáros (2001) ao utilizar-se, por exemplo, do conceito "igualdade substantiva" e em Löwy (2005) como ecossocialismo e ecomarxismo.

Assim, depara-se com desafios diante de danos, perdas, degradações, extinções e falta de apreensão sobre como o uso da técnica comporta a dominação (no âmbito da consciência e no plano material) sobre a natureza e sobre os homens e as mulheres, simultaneamente, e contribui para ampliação da desigualdade e da pobreza. As sucessivas catástrofes ambientais e "climáticas", desde Chernobyl à recente tragédia de Fukushima, permitem inferir que se está diante de uma crise estrutural não somente do capital, senão da sustentabilidade das espécies. Esse quadro, embora em proporções diferentes, revela um risco para todos(as), na medida em que passam a estar submetidos(as) a uma lógica mercantil, que traz em si o caráter historicamente desigual produzido e reproduzido pela colonialidade do poder.

\section{Referências}

BANCO MUNDIAL. Uma associação para o progresso do meio ambiente: o Banco Mundial na América Latina e no Caribe. Washington: Banco Mundial, 1994.

BURKETT, P. Marx and Nature: a Red and Green Perspective. New York: St. Martin's Press, 1999.

CHESNAIS, F. Orígenes comunes de la crisis económica y la crisis ecológica. Revista Praia Vermelha, Rio de Janeiro: UFRJ, v. 19, n. $2,2009$.

CHESNAIS, F.; SERFATI, C. "Ecologia" e condições físicas de reprodução social: alguns fios condutores marxistas. Crítica Marxista, n. 16, São Paulo: Boitempo, p. 1-40, 2003. 
CMMAD-Comissão Mundial sobre o Meio Ambiente e Desenvolvimento. Relatório Nosso Futuro Comum. Rio de Janeiro: Fundação Getúlio Vargas, 1991.

COUTINHO, R. "Crise ambiental" e desenvolvimento insustentável: a mitologia da sustentabilidade e a utopia da humanização do capitalismo "selvagem". Revista Praia Vermelha, Rio de Janeiro: UFRJ, v. 19, p. 21-36, 2009.

FERNANDES, M. Desenvolvimento sustentável. Antinomias de um conceito. Raízes, Campina Grande, v. 21, n. 2, p. 246-260, jul./dez. 2002.

FOLADORI, G. Los límites del desarollo sustentable. Montevideo: Ediciones de La Banda Oriental, 1999.

FOSTER, J. B. A ecologia de Marx: materialismo e natureza. Tradução de Maria Tereza Machado. Rio de Janeiro: Civilização Brasileira, 2010.

FOSTER, J. B.; CLARK, B. Imperialismo ecológico: a maldição do capitalismo. Disponível em: <http://bibliotecavirtual. clacso.org.ar/ar/libros/social/2004pt/10 foster.pdf $>$. Acesso em: 10 set. 2011.

FREITAS, R. de C. M. A construção de uma agenda para as questões de gênero, desastres socioambientais e desenvolvimento. Revista Estudos Feministas, v. 18, n. 3, p. 889-899, 2010.

FREY, K. A dimensão político-democrática nas teorias de desenvolvimento sustentável e suas implicações para a gestão local. Ambiente \& Sociedade, Campinas, n. 9, p. 115-148, jul./ dez. 2001.

FURTADO, C. O mito do desenvolvimento econômico. Rio de Janeiro: Paz e Terra, 1998.

GODARD, O. O desenvolvimento sustentável: paisagem intelectual. In: CASTRO, E.; PINTON, F. (Org.). Faces do trópico úmido. Conceitos e questões sobre desenvolvimento e meio ambiente. Belém: UFPA, 1997, p. 107-130.

LAFFERTY, W. M. The Politics of Sustentainable Development: Global Norms for National Implementation. Environmental Politics, v. 5, n. 2, p. 185-208, Summer,1996.

LAYRARGUES, P. P. Do ecodesenvolvimento ao desenvolvimento sustentável: evolução de um conceito? Revista Proposta, Rio de Janeiro, v. 24, n. 71, p. 1-5, 1997.

LEFF, E. Cultura democrática, gestión ambiental y desarrollo sustentable en América Latina. Cuadernos de Debate Internacional, Barcelona: Icaria Editorial, n. 4, p. 47-55, 1992.

Ecología y capital: racionalidad ambiental, democracia participativa y desarrollo sustentable. México/Argentina: SigloVeintiuno Editores, 1994.
LENZI, C. L. Sociologia ambiental: risco e sustentabilidade na modernidade. São Paulo: Anpocs; Edusc, 2005.

LOUREIRO, C. F. B. O movimento ambientalista e o pensamento crítico: uma abordagem política. Rio de Janeiro: Quartet, 2006a.

.(Org.). Sociedade e meio ambiente. A educação ambiental em debate. São Paulo: Cortez, 2006b.

LÖWY, M. Ecologia e socialismo. São Paulo: Cortez, 2005.

Crise ecológica, capitalismo, altermundialismo: um ponto de vista ecossocialista. INTERFACEHS: Revista de Gestão Integrada em Saúde do Trabalho e Meio Ambiente, v. 4, n. 3, p. 132-140, 2009.

MARX, K. Manuscritos econômico-filosóficos: primeiro manuscrito. 1844. Disponível em: 〈http://www.marxists.org/ portugues/marx/1844/manuscritos/>. Acesso em: 9 jun. 2011.

O capital: crítica da economia política. Coordenação e revisão de Paul Singer. Tradução de Regis Barbosa e Flávio R. Kothe. São Paulo: Nova Cultural, 1996. (Os Pensadores, livro 1, tomo 2).

MARX, K.; ENGELS, F. Manifesto do partido comunista. Tradução de Alvaro Pina. São Paulo: Global, 1988.

MÉSZÁROS, I. O desafio do desenvolvimento sustentável e a cultura da igualdade substantiva. Texto lido na conferência da Cúpula dos Parlamentares Latino-Americanos. Caracas, 2001. Tradução de Paulo Maurício. Disponível em: <http://www.meszaros.comoj.com/ ?q=category/5/94> . Acesso em: 16 set. 2011.

O desafio e o fardo do tempo histórico: o socialismo no século XXI. São Paulo: Boitempo, 2007.

MOTA, A. E.; SILVA, M. das G. e. A questão ambiental e o contraditório discurso da sustentabilidade. Revista Praia Vermelha, Rio de Janeiro: UFRJ, v. 19, p. 37-50, 2009.

ONU/PNUD. Organização das Nações Unidas e Programa das Nações Unidas para o Desenvolvimento. Objetivos de Desenvolvimento do Milênio. 2000. Disponível em: <http:// www.pnud.org.br/odm/index.php?lay $>$. Acesso em: 15 jul. 2011.

OPHULS, W.; BOYAN JR., A. Ecology and the Politics of Scarcity Revisited: the Unraveling of the American Dream. New York: W.H. Freeman, 1992.

PAULO NETTO, J.; BRAZ, M. Economia política: uma introdução crítica. São Paulo: Cortez, 2007.

PNUD- Programa das Nações Unidas para o Desenvolvimento. Projetos Meio Ambiente e Desenvolvimento. 2012. Disponível em: <http://www.pnud.org.br/projetos/meio ambiente/>. Acesso em: 12 set. 2011. 
PORTO-GONÇALVES, C. W. Geografia política e desenvolvimento sustentável. Terra Livre, São Paulo, n.11/12, p. 9-76, 1996.

O desafio ambiental. Rio de Janeiro: Record, 2004.

RAMOS, M. H. R. Desenvolvimento sustentável numa perspectiva crítica. 2010. Disponível em: <http://www. redecomunaverde.org/rede/index.php?option $=$ com content \&view=article\&id=68:dese>. Acesso em: 18 set. 2011.

REIS, M. J.; BLOEMER, N. M. S. (Org.). Hidrelétricas $e$ populações locais. Programa de Pós-Graduação em Antropologia Social da UFSC. Florianópolis: Editora da UFSC, 2001.

SACHS, I. Ecodesenvolvimento. Crescer sem destruir. São Paulo: Vértice, 1986.

SANCHÉZ, L. E. Avaliação de impacto ambiental: conceitos e métodos. São Paulo: Oficina de textos, 2008.

SILVA, M. das G. e. Questão ambiental e desenvolvimento sustentável: um desafio ético-político ao Serviço Social. São Paulo: Cortez, 2010.

\section{Notas}

1 Autores como Chesnaise Serfati (2003) afirmam que as formulações dos pensadores clássicos da área social, oriundos dos séculos 17 ao 19, dentre eles Marx, não podem ser definidas como ecológicas. E também autores como Löwy (2005), Porto-Gonçalves (2004) e Foster (2010, p. 38) postulam que a obra de Marx está "inextricavelmente atrelada a uma visão de mundo ecológica".

2 Para seidentificara contribuição do marxismo, noâmbito da discussão da questão ambiental, sugere-se a leitura de: André Gorz (primeiros escritos), Barry Commomer, Elmar Altvater, John Bellamy Foster, Guilhermo Foladori, Ian Angus, Joel Kovel, Juan Martinez-Allier, Francisco Fernandez Buey, Frieder Otto Wolf, Carlos Frederico Bernardo Loureiro, James O'Connor, Jorge Riechman, Jean-Paul Déléage, Jean-Marie Harribey, Manuel Sacristan Raymond Williams, Rudolf Bahro e outros que se expressam em revistas acadêmicas como Capitalism, Nature and Socialism, Ecologia Política, Montly Review e Crítica Marxista.

3 Para mais informações sobre a natureza em Marx eEngels, sugerese a leitura de: Formações econômicas pré-capitalistas (1987-8), Crítica ao Programa de Gotha (1875); e de Engels: Sobre o papel do trabalho na transformação do macaco em homem (1876) e Situação da classe operária na Inglaterra (1845).

4 Esse artigo se configura como resultado parcial das atividades desenvolvidas pelas autoras como pesquisadoras participantes do projeto "Situações de desastres: novas demandas e desafios ao trabalhointerdisciplinar", queéfinanciado pelaFundação deAmparo à Pesquisa e Inovação do Estado de Santa Catarina (Fapesc).
5 Para Löwy (2009, p. 135), o ecossocialismo configura-se como uma corrente de pensamento e ação ecológica que, “"...] longe de ser politicamente homogênea [...] representa uma tentativa original de articular as ideias fundamentais do socialismo marxista com as conquistas da crítica ecológica". O ecossocialismo representa uma ruptura tanto com o modelo expansionista do capital, como com a perspectiva produtivista do "socialismo real". Para os ecossocialistas (Joel Kovel, Michel Löwy, John Bellamy Foster, Paul Burkett, Martinez-Alier, entre outros), tanto a lógica do mercado e do lucro como o produtivismo burocrático do marxismo economicista vulgar são considerados modelos absolutamente incompatíveis com a urgente eimprorrogável exigência de preservação do meio ambiente.

6 Para mais informações, sugere-se a leitura de Godard (1997)e Frey (2001).

7 Em junho de 1973, em reunião do conselho administrativo do PNUMA, em Genebra surgiu o nome ecodesenvolvimento, formulada por Maurice Strong, contudo, o conceito foi ampliando por Ignacy Sachs, agregando, além das questões ambientais, as sociais, as de gestão participativa, a ética e a cultura.

8 Igualmente, Furtado (1998) desmistifica a ideia de que os países em desenvolvimento ou subdesenvolvidos podem atingir os padrões de vida dos países desenvolvidos por meio do incentivo ao crescimento econômico (confundido com "desenvolvimento"), aspecto este pouco considerado na abordagem hegemônica sobre o desenvolvimento sustentável.

9 AConstituição brasileira, por exemplo, em seu artigo 225 estabelece este direito.

10 Para exemplificar, salienta-se que a ONU através da campanha "Objetivos de Desenvolvimento do Milênio" coordenada pelo Programa das Nações Unidas para o Desenvolvimento (PNUD), lançada no ano 2000, traz como sétimo objetivo garantir a sustentabilidade ambiental e estabelece algumas metas. Para cada meta, há indicadores e projetos relacionados financiados pelas agências internacionais parceiras dos governos municipais, estaduais, federal, entidades públicas, privadas e organizações da sociedade civil de interesse público (ONU/PNUD, 2000). Já, o PNUD (2012) oferece aos parceiros apoio técnico, operacional e gerencial, por meio de acesso a metodologias, consultoria especializada e ampla rede de cooperação técnica internacional. 
Rosana de Carvalho Martinelli Freitas

romartin@matrix.com.br

Doutora em Sociologia Política pela Universidade Federal de Santa Catarina (UFSC)

Professora do Curso de Graduação e do Programa de Pós-Graduação em Serviço Social da Universidade Federal de Santa Catarina (PPGSS-UFSC)

\section{Camila Magalhães Nélsis}

camila_nelsis@hotmail.com

Assistente social

Mestranda do PPGSS-UFSC

\section{Letícia Soares Nunes}

leticia_snunes@hotmail.com

Assistente social

Mestre em Serviço Social-UFSC

UFSC - Programa de Pós-Graduação em Serviço Social

Campus Universitário Reitor João David Ferreira Lima

Bairro Trindade

Florianópolis - Santa Catarina

CEP: 88040-970 